\title{
The flux of shelf-borne dissolved organic carbon in the northwestern Pacific Ocean
}

\author{
HEEJUN HAN ${ }^{*}$, HYUNG-MI CHO', GUEBUEM KIM', \\ JEOMSHIK HWANG' \\ 'School of Earth and Environmental Sciences, Seoul National \\ University, 1 Gwanak-ro, Gwanak-gu, Seoul 08826, \\ Korea (*correspondence: hanheejun@snu.ac.kr)
}

We estimated the sources and fluxes of dissolved organic carbon (DOC) in the northwestern Pacific continental shelf including the East China Sea and the Yellow Sea, which is known as one of the largest continental shelves in the world. In order to determine the sources and fluxes of DOC, ${ }^{22} \mathrm{Ra}$ activities in seawater, radiocarbon $(\mathrm{C})$ in DOC, and stable carbon isotopes in DOC were measured for shelf waters collected in different seasons. The different water mass mixing ratios based on the ${ }^{22} \mathrm{Ra}$ activities against salinity plot showed that the Changjiang River was the major source of excess DOC during the summer, while there was significant supply of DOC produced in the continental shelf water duirng the winter and spring. The shelf-borne DOC was mostly marine in origin based on $\mathrm{C}$ values and younger ( $\mathrm{C}$ age) than that of the Kuroshio Current water. The net flux of DOC from the continental shelf was approximately 1.4 times greater than that from the Changjiang River discharge. Our results suggest that the continental shelf-borne DOC flux can play a significant role in marine carbon budget and cycle. 